\title{
Significance of mRNA and Protein Expression of MAC30 in Progression of Colorectal Cancer
}

\author{
Zeng-Ren Zhao, Li-Jing Zhang, Xin-Qi He, Zhi-Yong Zhang, Feng Zhang, Fang Li, \\ Yong-Bin Pei, Yue-Ming Hu, Ming-Wei Wang and Xiao-Feng Sun
}

\section{Linköping University Post Print}

N.B.: When citing this work, cite the original article.

Original Publication:

Zeng-Ren Zhao, Li-Jing Zhang, Xin-Qi He, Zhi-Yong Zhang, Feng Zhang, Fang Li, YongBin Pei, Yue-Ming Hu, Ming-Wei Wang and Xiao-Feng Sun, Significance of mRNA and Protein Expression of MAC30 in Progression of Colorectal Cancer, 2011, Chemotherapy, (57), 5, 394-401.

http://dx.doi.org/10.1159/000331716

Copyright: Karger http://www.karger.com/

Postprint available at: Linköping University Electronic Press

http://urn.kb.se/resolve?urn=urn:nbn:se:liu:diva-75033 
Significance of mRNA and protein expression of MAC30 in progression of colorectal cancer

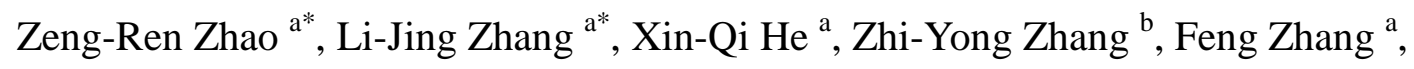
Fang $\mathrm{Li}^{\mathrm{a}}$, Yong-Bin Pei ${ }^{\mathrm{a}}$,Yue-Ming Hu ${ }^{\mathrm{b}}$, Ming-Wei Wang ${ }^{\mathrm{c}}$, Xiao-Feng Sun ${ }^{\mathrm{d}}$

Department of ${ }^{a}$ Surgical Oncology, ${ }^{c}$ Central Laboratory, First Hospital and ${ }^{b}$ Department of Pathology, Tangshan Gongren Hospital, Hebei Medical University, Shijiazhuang, China; ${ }^{\mathrm{d}}$ Division of Oncology, Department of Clinical and Experimental Medicine,University of Linköping, Linköping, Sweden

${ }^{*}$ Z-R Zhao and L-J Zhang contributed equally to this study.

Running title: MAC30 in colorectal cancer

\section{"Correspondence to:}

Xiao-Feng Sun, Professor, M.D., Ph.D.

Division of Oncology, Department of Clinical and Experimental Medicine, University of Linköping, Linköping, S-581 85, Sweden

Tel: +46-(0)10-1032066, Fax: +46-(0)10-1033090

E-mail: xiao-feng.sun@liu.se

This study was supported by the National Natural Science Foundation of China (No.30772115).

\section{Key words}

MAC30 C Colorectal cancer-HCT116 cells· RT-PCR· Western blot· DNA sequencing 


\section{Abstract}

Background: Meningioma-associated protein (MAC30), first described to be overexpressed in meningiomas, exhibits altered expression in certain human tumors. The aim of our study was to investigate the expression of MAC30 mRNA and its correlation with clinicopathological variables in human colorectal cancer (CRC). Methods: MAC30 mRNA expression was first examined in $55 \mathrm{CRCs}$, along with the samples from the matched distant normal and adjacent non-cancerous tissue by RT-PCR, further verified in 18 CRCs by qRT-PCR. MAC30 protein expression was detected by Western blot in 10 CRCs, and DNA sequencing was performed in one case of the paired CRC and the matched non-cancerous specimen. MAC30 mRNA expression in two colon cancer cell lines, HCT-116 ${ }^{\text {p53-/- }}$ and HCT-116 ${ }^{\text {p53+/+ }}$, was detected by qRT- PCR. Results: The mRNA expression of MAC30 was increased in CRC when compared with distant normal $(P<0.01)$ and adjacent non-cancerous mucosa $(P<0.01)$. The mean value of MAC30 mRNA expression in tumor located in the colon was higher than in the rectum $(0.677 \pm 0.419$ vs. $0.412 \pm 0.162, P=0.005)$. As the tumor penetrated the wall of the colon/rectum, MAC30 mRNA expression notably increased in tumors with $\mathrm{T} 3+\mathrm{T} 4$ stage compared to tumors with $\mathrm{T} 1+\mathrm{T} 2$ stage $(0.571 \pm 0.364$ vs. $0.404 \pm 0.115, P=0.014)$. MAC30 protein expression in CRCs was also remarkably elevated compared to the adjacent non-cancerous mucosa. There was no mutation in the coding region of MAC30 gene either in CRC or in the non-cancerous mucosa. mRNA expression of p53 was notably decreased in HCT-116 ${ }^{\text {p53-- }}$ than in HCT-116 ${ }^{\text {p53+/+ }}$, while MAC30 was not greatly varied. Conclusion: The 
overexpression of MAC30 might be involved in the development and aggressiveness of CRCs, especially in the colon. 


\section{Introduction}

Colorectal cancer (CRC) is one of the most common malignant tumors worldwide, with an estimated one million new cases and a half million deaths each year [1]. Many Asian countries, including China, have experienced an increase of 2-4 times in the incidence of CRC during the past few decades [2]. To reduce the mortality and improve treatment, a lot of studies have been performed in order to search for tumor biomarkers.

Meningioma-associated protein (MAC30, 17q11.2) was a recently identified protein, having a small segment of similarity to an apical gut membrane polyprotein of Haemonchus contortus, to olfactory receptor 30 of Mus musculus, and to cytochrome b in several organisms. MAC30 was first described to be overexpressed in meningiomas, and altered expression was also found in different types of human tumors [3-5]. MAC30 expressed at moderate levels in normal pancreatic acinar cells, strongly present in tubular complexes of chronic pancreatitis, and observed at low levels in most pancreatic cancer cells. The loss or reduction of MAC30 expression in pancreatic cancer suggests that this gene acts as a tumor suppressor in pancreatic cancer [4]. In contrast to pancreatic cancer, the expression of MAC30 was stronger in breast, stomach and colon cancers compared with the corresponding normal tissues [5-7], indicating the importance of MAC30 expression in different types of malignancies.

Not long ago, our research group found that, in CRC, MAC30 protein expression increased from distant normal mucosa to primary tumor and to metastasis in the 
lymph nodes, and was positively related to the expression of proliferating cell nuclear antigen (PCNA), p53, nucleoporin 88 (Nup88) and particularly interesting new cysteine-histidin rich protein (PINCH) [6]. Strong expression of MAC30 was related to a poor prognosis in CRC patients [6-7], indicating that MAC30 protein plays a great role in the development, invasion and metastasis of CRCs. Our question is whether MAC30 mRNA transcription is changed and whether it is related to the clinicopathological variables in CRC. 


\section{Patients and Methods}

\section{Patients and Specimens}

This study was approved by the Ethics Committee of Tangshan Worker's Hospital of Hebei Medical University. Fresh colorectal adenocarcinoma specimens and their adjacent non-cancerous tissue were obtained at the time of surgery from 55 cases of colorectal adenocarcinoma and immediately snap-frozen in liquid nitrogen. All patients were diagnosed and treated at the Tangshan Gongren Hospital (Tangshan, China) between January 2007 and December 2008. The fresh normal mucosa samples were collected at the same time. All of the patients were informed consent and none of the patients received preoperative radiotherapy or chemotherapy. The patient's gender, age, tumor location, histological type, grade of differentiation, invasive depth and lymph node metastasis were obtained from surgical and pathological records. The mean age of the patients was 57.6 years (range from 31-90 years), of which, the males account to $64 \%$, and the females $36 \%$. Tumors were located in the colon ( $\mathrm{n}=$ $26)$ or the rectum $(n=27)$, and 2 cases were lack of the information; non-mucinous adenocarcinomas $(n=36)$, mucinous/signet-ring cell carcinomas $(n=17)$ and 2 lost; tumors were graded as better (well + moderately, $n=43$ ), worse (poorly, $n=9$ ) differentiation and another 3 cases were unknown. All samples were examined by two pathologists (Zhi-Yong Zhang and Yue-Ming $\mathrm{Hu}$ ).

\section{Cell Culture}

Human colon carcinoma cell lines, HCT116 (a kind gift from Dr. B Vogelstein) with wild type p53 (HCT116 ${ }^{\mathrm{p} 53+/+}$ ) and truncated p53 missing 40 amino acid residues (HCT116 $\left.6^{\mathrm{p} 53-/-}\right)$ [8], was cultivated in McCoy's 5A medium (Sigma-Aldrich, St. Louis, MO) supplemented with 
10\% FBS (GIBCO, Invitrogen, Carlsbad, CA), 1.5 mM L-glutamine (GIBCO) and 1X PEST (GIBCO) at $37^{\circ} \mathrm{C}$ in a $5 \% \mathrm{CO}_{2}$ incubator.

\section{cDNA Synthesis and RT-PCR}

The tissue specimens were homogenized with a glass homogenizer. Total RNA was extracted from cell pellets and tissue samples using Trizol reagent (Invitrogen, Carlsbad, CA). Reverse transcription reaction was performed using $2 \mu \mathrm{g}$ of total RNA with Reverse Transcription System (Promega, San Luis Obispo, CA). The mRNA expression levels of the MAC30 were determined by conventional RT-PCR with GoTaq polymerase (Promega, San Luis Obispo, CA). Primer sequences of MAC30 and $\beta$-actin were as followed. MAC30-F: 5' -ACTGCTCAGAACCCACGTCT-3' , MAC30-R: $5^{\prime}$ - ATCATGCCACTGCCCTTTAC-3' , and $\beta$-actin-F: $5^{\prime}$ GGAAATCGTGCGTGACATTA-3' , $\beta$-actin-R: $5^{\prime}$ -

GGAGCAATGATCTTGATCTTC-3' . To quantify the expression levels of the target gene, $10 \mu \mathrm{l}$ PCR products were separated by $1.5 \%$ agarose gel electrophoresis and quantified by Gel Imaging System after ethidium bromide $(10 \mathrm{mg} / \mathrm{L})$ staining. The mRNA expression level of target gene was defined by the densitometry ratio of target gene to $\beta$-actin.

\section{Quantitative real-time $R T$-PCR}

The mRNA expression levels of the MAC30 and p53 were examined by quantitative real-time PCR using the SYBR Green Master Mix Kit and the ABI 7500 Real-Time PCR System (Applied Biosystems, Foster City, CA). Primers used for real-time RT-PCR were listed; MAC30-F: 5' -CCCAGCCTGGTTTAAGTCCTT-3' , 
MAC30-R: 5' -CCACTTGCAGCTTCCTTTGAG-3' ; p53-F: 5'

-TCAACAAGATGTTTTGCCAACTG-3' , p53-R: 5'

-ATGTGCTGTGACTGCTTGTAGATG-3' .Glyceraldehyde-3-phosphate

dehydrogenase (GAPDH) was used as an internal control of RNA integrity.

\section{Protein preparation and Western blot}

HCT-116 cells were firstly used to validate the MAC30 antibody. When the cells grow up to $10^{6}$, they were collected, washed in PBS and lysed in RIPA buffer along with the frozen colorectal tissues, containing $150 \mathrm{mM} \mathrm{NaCl}, 1 \%$ Triton $\mathrm{X}-100,0.1 \%$ SDS, 50mM Tris (pH 8.0) and a Complete ${ }^{\mathrm{TM}}$ Mini Protease Inhibitor Cocktail Tablet (Roche). Protein concentration was determined with the colorimetric BCA protein assay reagent (Pierce, Woburn, MA). Samples containing 50 $\mu$ g of total protein were boiled for 5 minutes in the presence of 2-mercaptoethanol and dithiothreitol. Solubilized proteins were separated by electrophoresis in 10\% SDS polyacrylamide gels and transferred to the polyvinylidene fluoride membranes (Millipore Corporation, Billerica, MA) by electroblotting in $25 \mathrm{mM}$ Tris, $192 \mathrm{mM}$ glycine, 20\% methanol (pH 8.3). The polyvinylidene fluoride membranes were washed with TBSTween 20 for 5 minutes with five changes and blocked with blocking buffer (5\% nonfat dry milk solution) and incubated for 2 hours on an orbital shaker at room temperature. Then the membranes were incubated with a monoclonal antibody MAC30 1-19 [3], diluted 1:5 in $5 \%$ nonfat milk/TBS-T overnight at $4{ }^{\circ} \mathrm{C}$. The membranes were rinsed with TBSTween 20 and incubated with peroxidase conjugated goat anti-mouse immunoglobulins (1:5,000, Zhongshan Gold Bridge Biotechnology, China) in 5\% 
nonfat milk, for 2 hours on an orbital shaker at room temperature. The membranes were washed with TBS-Tween 20 between each incubation step, for 5 minutes with five changes on an orbital shaker at room temperature. At last, the membranes were stained by DAB. MAC30 protein migrates in sodium dodecyl polyacrylamide gel as a $24 \mathrm{kDa}$ monomer, reaction of the MAC30 antibody with the protein resulted in the bands, which could be detected against the standard marker used.

\section{Nucleotide sequence analysis}

MAC30 gene coding region sequence (CDS) was analyzed by extracting genomic DNA from the fresh CRC and non-cancerous colon tissues with a tissueGen DNA kit (CWBIO, China) according to its manufacturer's instructions. CDS of the MAC30 gene (Gene ID: 27346, nt 146 to $271 ; 6409$ to $6553 ; 7440$ to 7699 ) was directly PCR-amplified in a thermal cycler. The sequences of primers used for MAC30 analysis were listed in Table 1. PCR conditions were as follows: 1 cycle at $95^{\circ} \mathrm{C}$ for 4 minutes, 35 cycles at $95^{\circ} \mathrm{C}$ for 40 seconds, respective annealing temperature for 40 seconds, and at $72^{\circ} \mathrm{C}$ for 40 seconds, followed by 1 cycle at $72^{\circ} \mathrm{C}$ for 10 minutes. After confirmed by agarose electrophoresis and ethidium bromide staining, the PCR products were purified and automatically sequenced with an ABI PRISM 3730 (Applied Biosystems, Foster City, CA), then analyzed with Chromas software version 2.0 (Gene Codes Corporation, Ann Arbor, MI). All sequencing reactions were performed in both forward and reverse directions, by independent PCR.

\section{Statistical Analysis}


Statistical analysis was performed using the Statistical Package for Social Science (SPSS) software (version13.0, SPSS, Chicago, IL). Relative levels of MAC30 mRNA expression (MAC30/ $\beta$-actin) were expressed as mean \pm standard deviation (SD). The difference of MAC30 mRNA expression among CRC, adjacent non-cancerous mucosa samples and distant mucosa was tested by One Way ANOVA. Associations between MAC30 mRNA expression and clinical parameters were analyzed by Student's $t$ test or ANOVA. Differences with $P<0.05$ were considered to be statistically significant. 


\section{Results}

\section{mRNA expression of MAC30 in CRC, adjacent and distant normal mucosa}

Fig. 1 shows the difference of MAC30 mRNA expression in CRC, the matched adjacent non-cancerous mucosa and distant normal mucosa. MAC30 mRNA expression in CRC was notably increased than that in the adjacent and distant normal mucosa (CRC vs. adjacent non-cancerous mucosa; CRC vs. distant normal mucosa, the both relationships: $P<0.01)$.
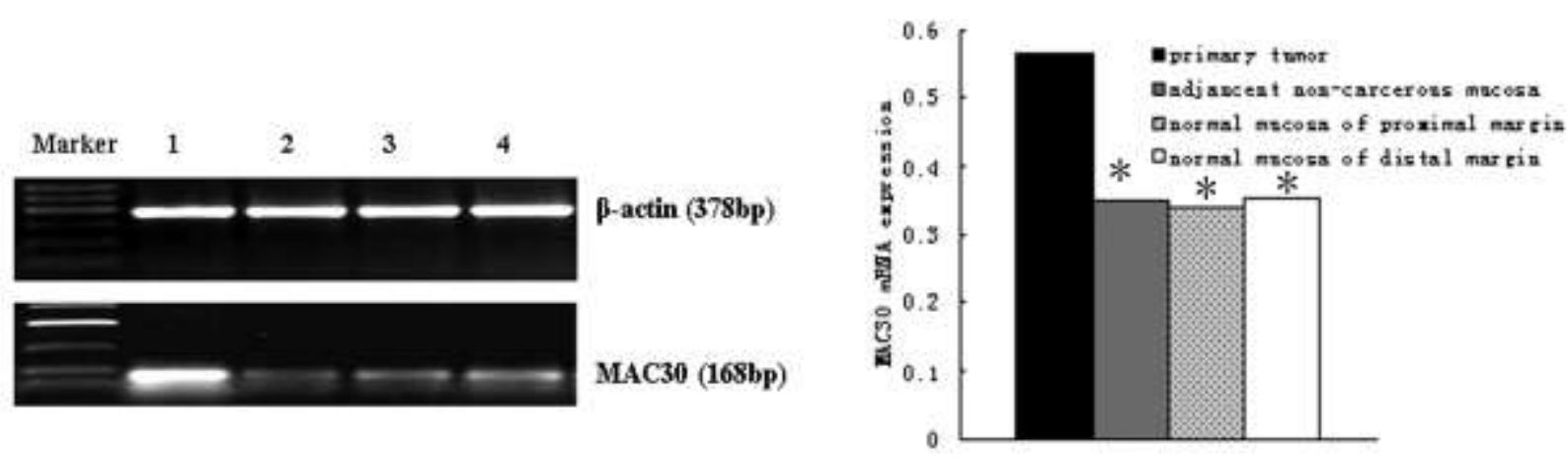

Fig. 1. Expression of MAC30 mRNA in different sites of colorectal tissue. RT-PCR products of MAC30 was detected by electrophoresis. $\beta$-actin, as the standared, was also examined. Marker, 100-600bp ladder; 1, colorectal tumor; 2 adjacent noncancerous mucosa; 3 , proximate normal mucosa; and 4, distant normal mucosa. MAC30 mRNA expression level was defined by the densitometry ratio to $\beta$-actin. On the histogram, MAC30 mRNA expression in CRC was notably increased compared to the other three groups. ${ }^{*} P<0.01$.

To further verify the above results, quantitative real-time RT-PCR was performed in 18 CRC samples, and MAC30 mRNA expression in CRC was greatly elevated compared with the adjacent non-cancerous mucosa and distant normal mucosa, which was consistent with the conventional RT-PCR results (Fig. 2). 


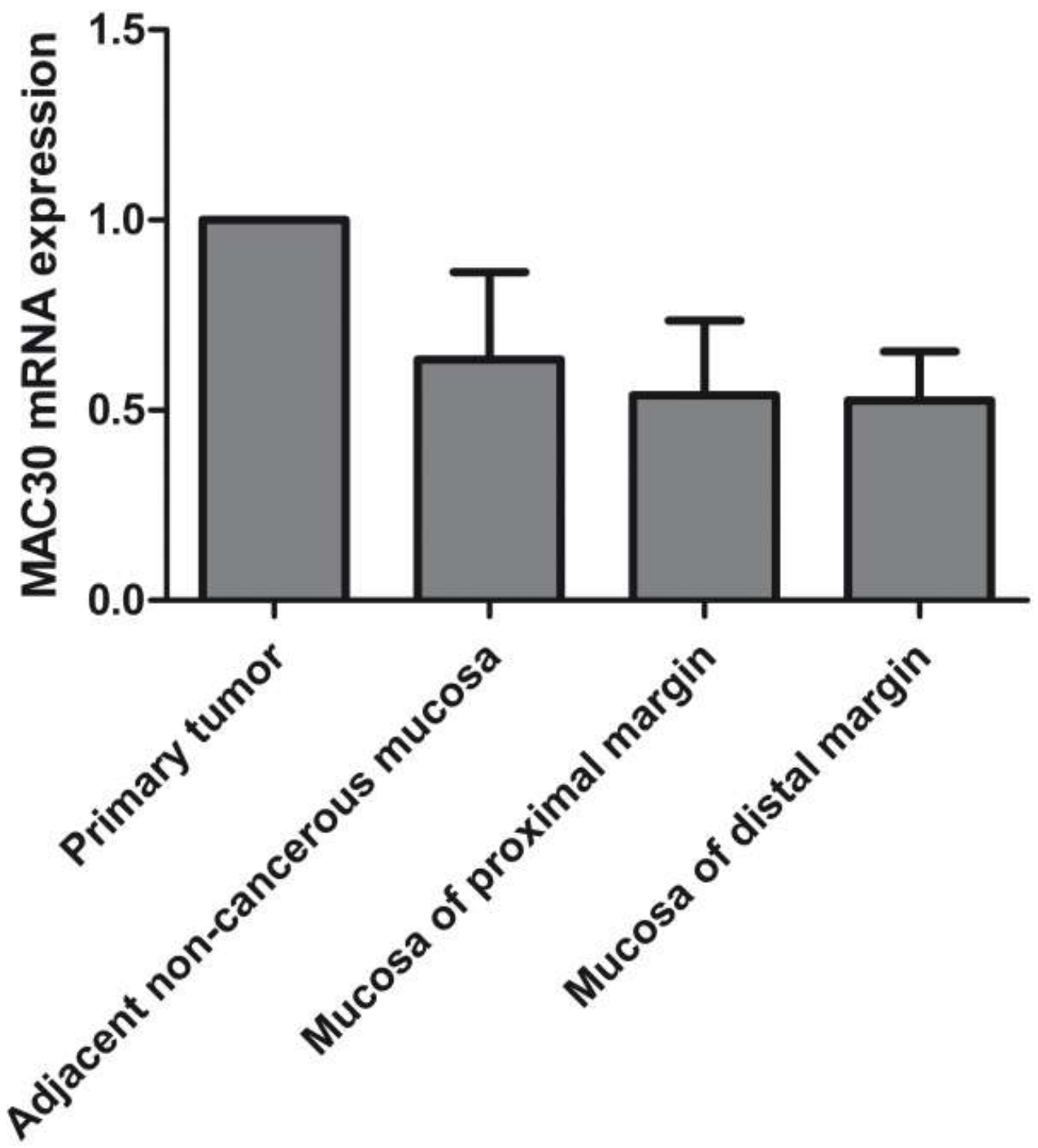

Fig. 2. Quantitative real-time RT-PCR results. mRNA values of MAC30 in different colorectal tissue samples were normalized to the expression of GAPDH, and we defined the level of MAC30 in primary tumor of CRC as 1, in the adjacent non-cancerous mucosa, mucosa of proximal and distant margin, MAC30 mRNA expression was notably decreased. $* P<0.01$. 


\section{Relationship between MAC30 mRNA expression and Clinicopathological}

\section{Characteristics}

The correlation between MAC30 mRNA expression and the clinicopathological characteristics is shown in Table 2. MAC30 mRNA expression was significantly correlated with tumor location. The mean value of MAC30 mRNA expression was higher in tumors located in the colon $(0.677 \pm 0.419)$ than in tumors located in the rectum $(0.412 \pm 0.162, P=0.005)$. MAC30 mRNA expression was also related to the depth of tumor invasion. MAC30 mRNA expression was notably elevated in tumors with $\mathrm{T} 3+\mathrm{T} 4$ stage $(0.571 \pm 0.364)$ compared with tumors with $\mathrm{T} 1+\mathrm{T} 2$ stage $(0.404 \pm$ $0.115, P=0.014)$. MAC30 expression in mucinous/signet-ring cell carcinomas had a trend of increase compared with that in non-mucinous carcinomas $(0.620 \pm 0.378 v s$. $0.504 \pm 0.321)$ although the difference was not statistically significant $(P=0.253)$. However, MAC30 mRNA expression was not correlated with the patients' gender, age, lymph node status, distant metastasis and differentiation $(P>0.05)$.

\section{Assessment of MAC30 and p53 in HCT116 cells}

We examined the expression of MAC30 and p53 in HCT116 wild type ${\text { (HCT } 116^{\mathrm{p} 53+/+} \text { ) and mutated type (HCT116 }}^{\mathrm{p} 53-/-)}$ by using semiquantitative RT-PCR. The results showed that $\mathrm{p} 53$ expression was greatly reduced in HCT116 p53-- $^{\text {(Fig. 3A) }}$ compared with HCT116 ${ }^{\mathrm{p} 53+/+}$, while MAC30 did not change on the two cell lines. Quantitative real-time RT-PCR results confirmed that p53 expression in HCT116 ${ }^{\mathrm{p} 53-/-}$ was significantly decreased, while MAC30 mRNA expression was found to be unchanged (Fig. 3B). 

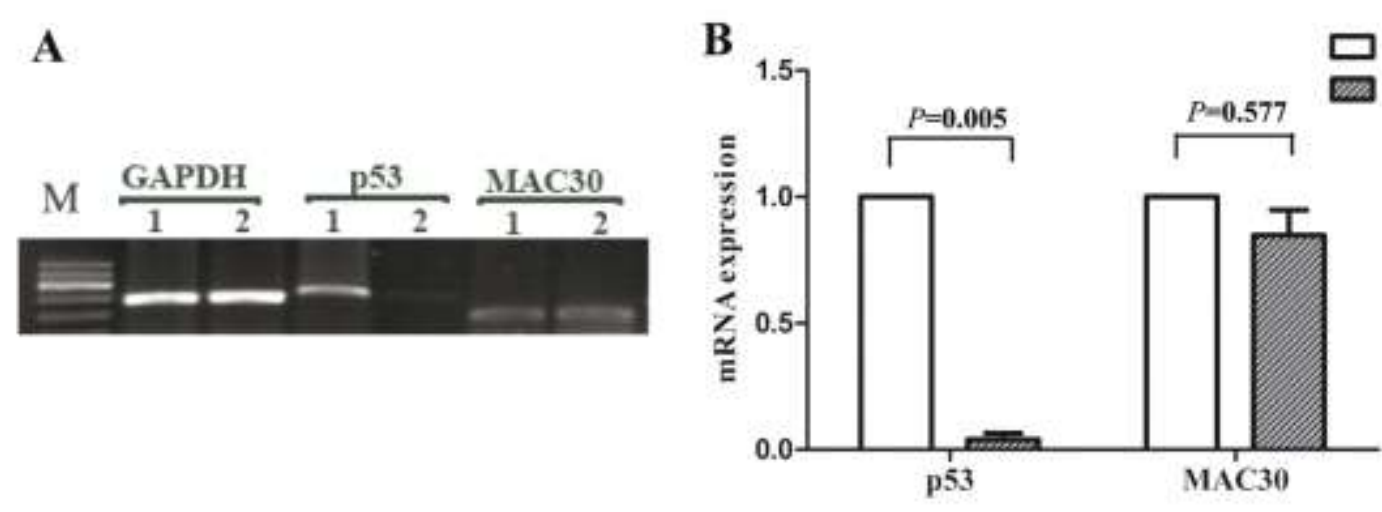

Fig. 3. MAC30 and p53 expression in human colon carcinoma cell lines. Relative MAC30 and p53 expression were determined by conventional RT-PCR (A) and quantitative real-time RT-PCR (B). GAPDH was used to normalise the template amount. 1 represents HCT116 wild type ( $\mathrm{HCT} 116^{\mathrm{p} 53+/+}$ ) and 2 represents HCT116 mutated type ( $\left.\mathrm{HCT} 116^{\mathrm{p} 53-/-}\right)$.

\section{Western Blot Analysis}

Lysates from HCT-116 cells were performed SDS-PAGE to validate the MAC30 antibody. As shown in Fig. 4A, a band was seen at $\sim 24 \mathrm{kDa}$, which was consistent with the description of the MAC30 antibody. We further examined MAC30 protein expression in $\mathrm{CRC}$ and adjacent non-cancerous mucosa to understand the difference by Western blot. The bands seen in human colon tissue (Fig. 4B) were the same as those found in HCT-116 cells (Fig. 4A), which indicated that these bands represent authentic MAC30, not cross-reacting protein. The expression of MAC30 protein in CRC was stronger than that in the adjacent non-cancerous mucosa (Fig. 4C).

\section{DNA sequencing results}

We sequenced the all of the coding nucleotides (528 base pairs, nt 146 to 271; 6409 to $6553 ; 7440$ to 7699 ), that are distributed to three exons and regrettably there was no any difference between the tumor and the matched non-cancerous mucosa. The all of the nucleotides were the same with the original sequence (Pubmed, Gene 
ID: 27346) and there were no mutations either in the tumor or the non-cancerous mucosa (Fig. 5).

A

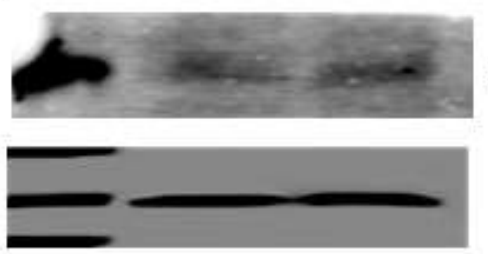

$\operatorname{MAC} 30(24 \mathrm{KD})$

$\beta-\operatorname{actin}(42 \mathrm{KD})$

B

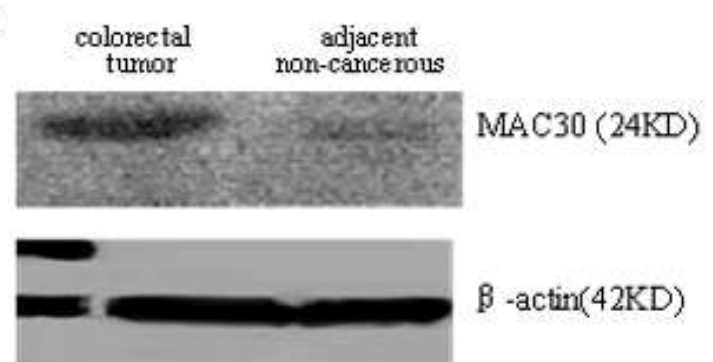

C

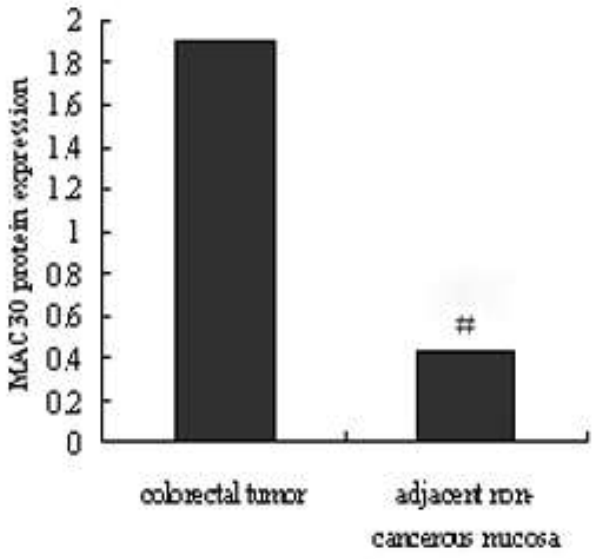

Fig. 4. MAC30 protein expression. A: MAC30 protein in HCT-116 cell lines, MAC30 was at about 24KD. B: MAC30 protein in colorectal tumor tissue and adjacent non-cancerous mucosa. MAC30 expression in colorectal tumor was much higher than that in the adjacent non-cancerous mucosa, $* P<0.01(\mathrm{C})$. 


\section{Discussion}

In the present study, we observed that MAC30 mRNA expression in CRC was significantly increased compared to the matched distant or adjacent non-cancerous mucosa. Up to now, only one study reported MAC30 mRNA overexpressed in 40 colon cancers and 27 normal tissue samples. However, the samples did not match in that study, it was shown an increased level of MAC30 mRNA in primary tumors compared to the normal samples [5]. And an increased level of MAC30 mRNA was shown in breast cancers compared to normal breast tissue, but there was significantly decreased MAC30 in pancreatic and renal cancers [5]. Shortly after, Wilcox et al [9] have found the expression of TMEM97, encoding MAC30 protein, was suppressed 2.4-fold in the ovarian cancer samples relative to normal ovarian surface epithelial cells. Our present data of MAC30 mRNA expression significantly increased in the tumor compared with the normal mucosa was in line with our previous immunostaining results observed in CRCs, where MAC30 expression was increased from distant normal mucosa to CRC [6]. The results of Western blot performed in the present study also confirmed that the expression of MAC30 protein in CRC notably upregulated than that in the adjacent non-cancerous mucosa. Taken together, either mRNA or protein of MAC30 expression was increased in CRC compared to normal colorectal mucosa, indicating that MAC30 may function as an oncogene and play an important role in the development of CRC. 
CDS1

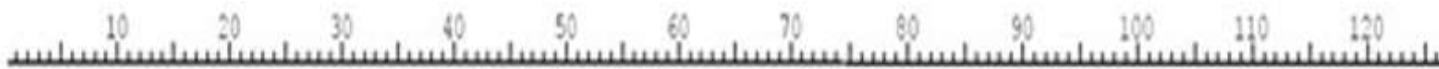

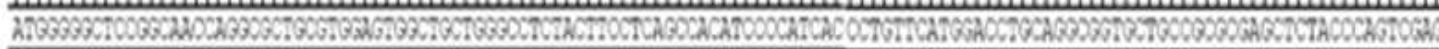

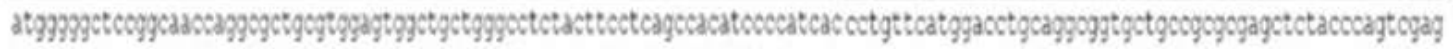
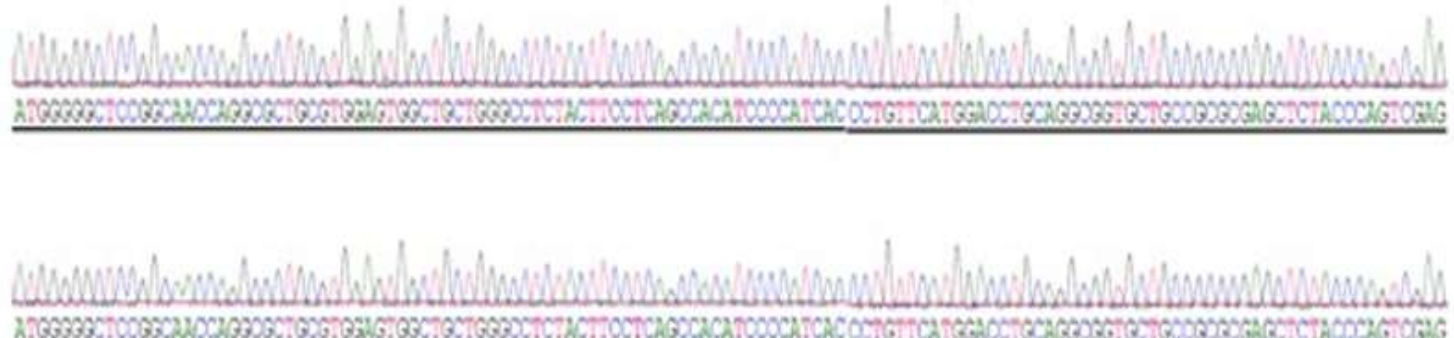
$\operatorname{CDS} 2$

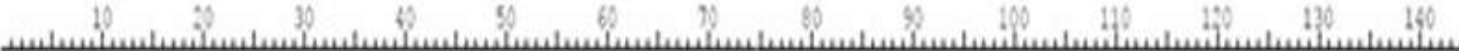

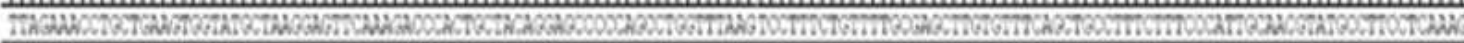

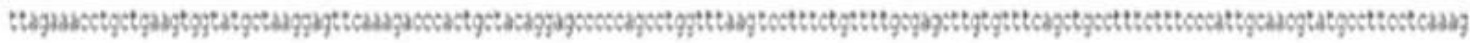

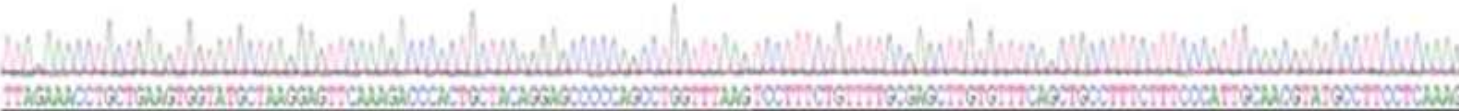

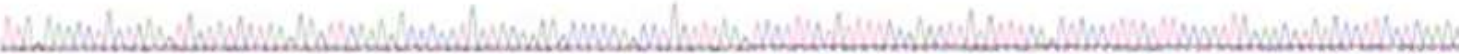

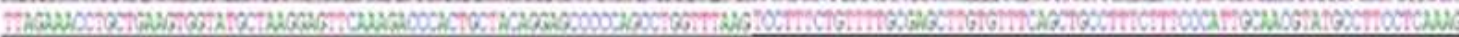

\section{CDS3}

19.

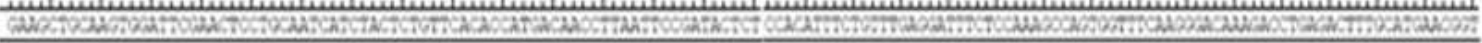

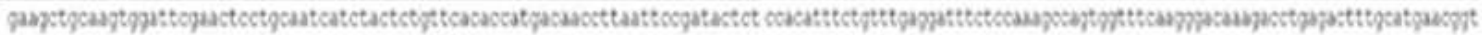
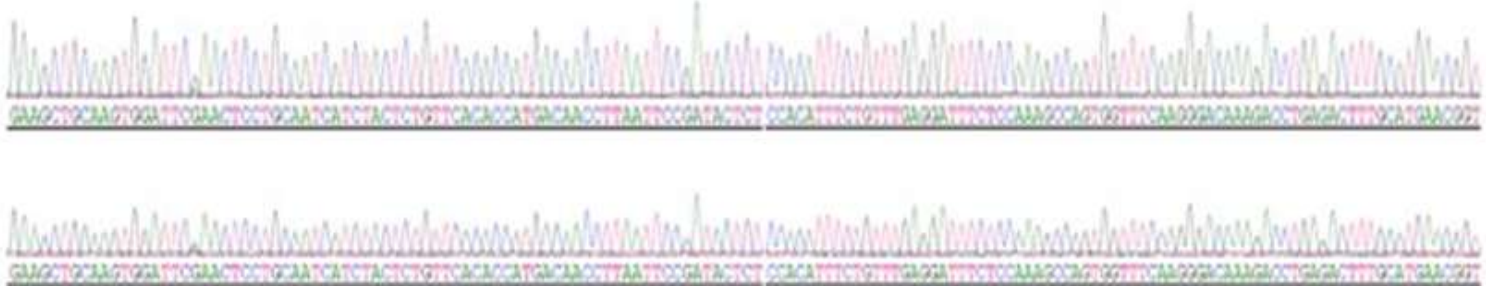

Fig. 5. DNA sequencing of MAC30 CDS. The nucleotide of MAC 30 gene CDS was sequenced and listed. The arrows on the right indicate the different sequence. In each CDS , the black arrows was the original sequence in the Gene Bank, the red arrows indicate the analyzed sequence of colon tumor and the green arrows was the sequence of the matched non-cancerous mucosa. 
In the present study, we also analysed the relationship of the MAC30 mRNA with clinicopathological variables, and found that overexpression of MAC30 mRNA was closely associated with the infiltrate depth and the tumor location, the both being the factors that were related to the prognosis of the patients with CRC [10]. With the increase of depth of invasion, MAC30 mRNA expression notably elevated. When the tumor invaded to the serosal layer, the level was much higher compared to those in the layer of mucous and muscular. Our previous studies reported that overexpression of MAC30 protein in the cytoplasm of oral squamous cell carcinoma may predict nodal metastasis and poor differentiation [11], and that the strong expression of MAC30 protein in the metastasis of the lymph node was related to an unfavorable outcome of CRC patients [6]. Therefore, we can see that MAC30, not only its protein but also mRNA, may be biomarkers to be implicated in the development and prognosis of CRC.

Tumor location was another factor that closely associated with the progression of CRC in relation to biological features. Current study showed that MAC30 mRNA expression in colon cancers was significantly higher than in rectal cancer. Several studies have suggested that the patients with colon cancer had a better prognosis than those with rectal cancer [12]. And one study has reported that the orotate phosphoribosyltransferase level was significantly higher in colon tumors than in rectal tumors [13]. However, tumors in distal colon cancer and left-sided colon tumor location were significantly correlated with poor overall survival [14], which might related to the chromosome instability, for example, K-ras mutation, p53 and 
APC/ $\beta$-catenin. Here, we have shown a new factor, MAC30, which may be also involved in cancer development in the different sites.

In the present study, MAC30 mRNA expression in mucinous/signet-ring cell carcinomas had a trend of increase, compared with non-mucinous carcinomas. In our previous study, we found that MAC30 was positively related to $\mathrm{PINCH}$, Nup88 and p53 expression [6]. PINCH is the protein involved in stromal related tumor development and aggressiveness [15-16] and the frequency of PINCH strong expression in mucinous and signet-ring cell carcinomas was higher compared to non-mucinous carcinomas [17]. More interestingly, strong immunostaining stroma for $\mathrm{PINCH}$ at the invasive margin is an independent prognostic indicator in $\mathrm{CRC}$ patients [18]. MAC30 mRNA was positively related to PINCH and Nup88 mRNA (data not shown), which was in line with the protein. MAC30 acts as a primary transcriptional target of p53 and could be down-regulated by p53 [19]. We could speculate that the high expression of MAC30 in CRC might correlate with p53 mutation. Therefore we examined the expression of p53 and MAC30, in two colon cancer cell lines, HCT-116 p53-/- and HCT-116 ${ }^{\mathrm{p} 53+/+}$, the results showed that mRNA expression of p53 was notably decreased in HCT-116 ${ }^{\text {p53-/ }}$ than in HCT-116 ${ }^{\text {p53+/+ }}$, while MAC30 was not greatly varied, which was similar to the findings of FXYD3 [20], where FXYD3 expression is dramatically increased after f luoropyrimidine 5-fluorouracil exposure only in the cell line with a functional p53, while FXYD3 expression is unchanged in a p53-null cell line. Our previous study found FXYD3 was highly expressed in primary tumor compared to adjacent normal mucosa and tended to be positively related to the 
expression of p53 [21].Hanski et al [22] has found that the mutation frequency of p53 was significantly different in colorectal mucinous and non-mucinous adenocarcinomas. Interaction and mechanism of MAC30 and p53 in CRC need to be further investigated.

We have sequenced the all of the coding nucleotides (528 base pairs) of MAC30 gene, and did not find any mutation. We could not propose yet that the difference of MAC30 mRNA and protein in CRC from normal mucosa was resulted from some mutations since we only examined one paired case, it is necessary to examine more cases to validate the result. However, we might presume that there are some changes in the introns of the gene or even methylation, leading to MAC30 overexpression in CRC, A study showed an intronic single nucleotide polymorphism (IVS1+12 C $>\mathrm{T}$ ) in one case of 39 ovarian cancer samples [9].

\section{Conclusion}

In the present study, the expression of MAC30 was remarkably elevated in CRC compared to the adjacent non-cancerous and distant normal mucosa. The overexpression of MAC30 might be involved in the development and aggressiveness of CRCs, especially in the colon. 


\section{Acknowledgments}

We would like to thank Prof. Hanswalter Zentgraf, Applied Tumor Virology,

University of Heidelberg, Heidelberg, Germany, for providing the MAC30 antibody.

We also thank Dr. B Vogelstein, Johns Hopkins University, Baltimore, for presenting

HCT-116 cells. This study was supported by the National Natural Science Foundation of China (No.30772115). 


\section{References}

1 Jemal A, Siegel R, Ward E, Murray T, Xu J, Thun MJ: Cancer statistics, 2007. CA Cancer J Clin 2007; 57: 43-66.

2 Sung JJ, Lau JY, Goh KL, Leung WK: Increasing incidence of colorectal cancer in Asia: implications for screening. Lancet Oncol 2005; 6: 871-876.

3 Murphy M, Pykett MJ, Harnish P, Zang KD, George DL: Identification and characterization of genes differentially expressed in meningiomas. Cell Growth Differ 1993; 4: 715-722.

4 Malhotra K, Luehrsen KR, Costello LL,Raich TJ, Sim K, Foltz L, Davidson S, Xu H, Chen A, Yamanishi DT, Lindemann GW, Cain CA, Madlansacay MR, Hashima SM, Pham TL, Mahoney W, Schueler PA: Identification of differentially expressed mRNAs in human fetal liver across gestation. Nucleic Acids Res 1999; 27: 839-847.

5 Kayed H, Kleeff J, Ding J, Hammer J, Giese T, Zentgraf H, Buchler MW, Friess $\mathrm{H}$ : Expression analysis of MAC30 in human pancreatic cancer and tumors of the gastrointestinal tract. Histol Histopathol 2004; 19: 1021-1031.

6 Moparthi SB, Arbman G, Wallin A, Kayed H, Kleeff J, Zentgraf H, Sun XF: Expression of MAC30 protein is related to survival and biological variables in primary and metastatic colorectal cancers. Int J Oncol 2007; 30: 91-95.

7 Zhang ZY, Zhao ZR, Adell G, Jarlsfelt I, Cui YX, Kayed H, Kleeff J, Wang MW, Sun XF: Expression of MAC30 in rectal cancers with or without preoperative radiotherapy. Oncology 2006; 71: 259-265. 
8 Bunz F, Dutriaux A, Lengauer C et al. Requirement for p53 and p21 to sustain G2 arrest after DNA damage. Science 1998; 282: 1497-1501.

9 Wilcox CB, Feddes GO, Willett-Brozick JE, Hsu LC, DeLoia JA, Baysal BE. Coordinate up-regulation of TMEM97 and cholesterol biosynthesis genes in normal ovarian surface epithelial cells treated with progesterone: implications for pathogenesis of ovarian cancer. BMC Cancer 2007; 7: 223.

10 Greene FL, Page DL, Fleming ID, Fritz A, Balch CM, Haller DG, Morrow M: (eds) (2002) AJCC cancer staging manual, 6th edn. Springer, New York.

11 Yan BY, Wang DW, Zhu ZL, Yang YH, Wang MW, Cui DS, Zhang H, Sun XF: Overexpression of MAC30 in the cytoplasm of oral squamous cell carcinoma predicts nodal metastasis and poor differentiation. Chemotherapy 2010; 56: 424-428.

12 Rosenberg R, Maak M, Schuster T, Becker K, Friess H, Gertler R: Does a rectal cancer of the upper third behave more like a colon or a rectal cancer? Dis Colon Rectum 2010; 53: 761-70.

13 Sumi T, Katsumata K, Tsuchida A, Ishizaki T, Shimazu M, Aoki T. Correlations of clinicopathological factors with protein expression levels of thymidylate synthase, dihydropyrimidine dehydrogenase and orotate phosphoribosyltransferase in colorectal cancer. Chemotherapy 2010; 56: 120-6.

14 Kang H, Min BS, Lee KY, Kim NK, Kim SN, Choi J, Kim H: Loss of E-cadherin and MUC2 expressions correlated with poor survival in patients with stages II and III colorectal carcinoma. Ann Surg Oncol 2011; 18: 711-9. 
15 Zhu Z, Yang Y, Zhang Y, Wang Z, Cui D, Zhang J, Wang M, Sun XF: PINCH expression and its significance in esophageal squamous cell carcinoma. Dis Markers 2008; 25: 75-80

16 Zhang HZ, Li XH, Zhang X, Zhang ZY, Meng YL, Xu SW, Zheng Y, Zhu ZL, Cui DS, Huang LX, Yan BY, Sun XF: PINCH Protein Expression in Normal Endometrium, Atypical Endometrial Hyperplasia and Endometrioid Endometrial Carcinoma. Chemotherapy 2010; 56: 291-297.

17 Zhao ZR, Zhang ZY, Cui DS, Jiang L, Zhang HJ, Wang MW, Sun XF: Particularly interesting new cysteine-histidine rich protein expression in colorectal adenocarcinomas. World J Gastroenterol 2006; 12: 298-301.

18 Gao J, Arbman G, Rearden A, Sun XF: Expression of PINCH protein is an indepependent prognostic factor in colorectal cancer patients. Neoplasia 2004; 6: 796-801.

19 Kannan K, Amariglio N, Rechavi G, Jakob-Hirsch J, Kela I, Kaminski N, Getz G, Domany E, Givol D: DNA microarrays identification of primary and secondary target genes regulated by p53. Oncogene 2001; 20: 2225-2234.

20 Maxwell PJ, Longley DB, Latif T, Boyer J, Allen W, Lynch M, McDermott U, Harkin DP, Allegra CJ, Johnston PG: Identification of 5-fluorouracil-inducible target genes using cDNA microarray profiling. Cancer Res 2003; 63: 4602-4606.

21 Widegren E, Onnesjö S, Arbman G, Kayed H, Zentgraf H, Kleeff J, Zhang H, Sun XF.Expression of FXYD3 protein in relation to biological and clinicopathological variables in colorectal cancers. Chemotherapy 2009; 55: 407-13. 
22 Hanski C, Tiecke F, Hummel M, Hanski ML, Ogorek D, Rolfs A, Schmitt-Gräff A, Stein H, Riecken EO: Low frequency of p53 gene mutation and protein expression in mucinous colorectal carcinomas. Cancer Lett 1996; 103: 163-170. 
Table1. Primers used for MAC30 DNA sequencing

\begin{tabular}{lccc}
\hline MAC30 & & Pimer sequence $\left(5^{\prime}-3^{\prime}\right)$ & Product \\
\hline CDS1 & forward & CAATGGAAGCGGTCTGCCT & $572 \mathrm{bp}$ \\
& reverse & GGACACCACTTCATCCAGACTAC & \\
& forward & CAAAGAAGGGGCTGGAAGA & $443 \mathrm{bp}$ \\
CDS2 & reverse & TTCTGGGACCTGATTTCTGAGT & \\
& forward & TGCCTTCTGATCCTCTCACCTA & $761 \mathrm{bp}$ \\
\hline
\end{tabular}


Table 2. Relationship of MA30 mRNA and clinicopathological variables in colorectal cancer

\begin{tabular}{|c|c|c|c|c|}
\hline Variables & $\mathrm{n}$ & $\begin{array}{c}\text { MAC30 mRNA } \\
\text { Expression } \\
\text { Mean } \pm \text { SEM }^{\text {a }}\end{array}$ & $t / F$-value & $P$-value \\
\hline Gender & $\mathrm{n}=55$ & & $t=-0.133$ & 0.895 \\
\hline Male & 35 & $0.532 \pm 0.358$ & & \\
\hline Female & 20 & $0.544 \pm 0.301$ & & \\
\hline Age(years) & $\mathrm{n}=55$ & & $t=0.491$ & 0.626 \\
\hline$<60$ & 18 & $0.568 \pm 0.298$ & & \\
\hline$\geq 60$ & 37 & $0.520 \pm 0.356$ & & \\
\hline Tumor location & $\mathrm{n}=53$ & & $t=-3.018$ & $0.005^{\mathrm{b}}$ \\
\hline Colon & 26 & $0.677 \pm 0.419$ & & \\
\hline Rectum & 27 & $0.412 \pm 0.162$ & & \\
\hline Infiltrate depth & $\mathrm{n}=55$ & & $t=-2.548$ & $0.014^{\mathrm{b}}$ \\
\hline $\mathrm{T} 1+\mathrm{T} 2$ & 10 & $0.404 \pm 0.115$ & & \\
\hline $\mathrm{T} 3+\mathrm{T} 4$ & 45 & $0.571 \pm 0.364$ & & \\
\hline Lymph node status & $\mathrm{n}=55$ & & $F=1.514$ & 0.23 \\
\hline N0 & 32 & $0.534 \pm 0.309$ & & \\
\hline N1 & 14 & $0.466 \pm 0.213$ & & \\
\hline $\mathrm{N} 2$ & 9 & $0.708 \pm 0.514$ & & \\
\hline Distant metastasis & $\mathrm{n}=55$ & & $t=0.128$ & 0.899 \\
\hline M0 & 46 & $0.544 \pm 0.359$ & & \\
\hline M1 & 9 & $0.559 \pm 0.209$ & & \\
\hline TNM stage & $\mathrm{n}=55$ & & $F=0.917$ & 0.439 \\
\hline I & 6 & $0.375 \pm 0.121$ & & \\
\hline II & 20 & $0.521 \pm 0.298$ & & \\
\hline III & 18 & $0.627 \pm 0.452$ & & \\
\hline IV & 11 & $0.559 \pm 0.209$ & & \\
\hline Histological type & $\mathrm{n}=53$ & & $t=1.157$ & 0.253 \\
\hline Non-mucinous & 36 & $0.504 \pm 0.321$ & & \\
\hline $\begin{array}{l}\text { Mucinous/signet-ring } \\
\text { cell carcinoma }\end{array}$ & 17 & $0.620 \pm 0.378$ & & \\
\hline Differentiation & $\mathrm{n}=52$ & & $t=-1.011$ & 0.317 \\
\hline Well+Moderately & 43 & $0.502 \pm 0.311$ & & \\
\hline Poorly & 9 & $0.617 \pm 0.313$ & & \\
\hline
\end{tabular}

